\title{
Copper(II)-Catalyzed Enantioselective Intramolecular Carboamination of Alkenes
}

\author{
Wei Zeng and Sherry R. Chemler ${ }^{*}$ \\ Department of Chemistry, University at Buffalo, The State University of New York, Buffalo, New \\ York 14260
}

The transition-metal mediated intramolecular carboamination of alkenes is a direct method for complex nitrogen heterocycle synthesis. A number of research groups have investigated this transformation in recent years. ${ }^{1}$ The catalytic asymmetric carboamination of alkenes is an obvious challenge for these reactions, and has been realized rarely. ${ }^{1 \mathrm{~d}}$ Herein is described a novel copper(II)-catalyzed asymmetric carboamination reaction that involves intramolecular addition of arylsulfonamides across terminal alkenes to provide chiral sultams. Sultams and sulfonamides are common components of biologically active small molecules. ${ }^{2}$

The copper-facilitated synthesis of heterocycles via addition of heteroatoms to alkenes and alkynes is an important area in organic synthesis. ${ }^{3}$ We have recently reported the first copper (II)-facilitated intramolecular carboamination of alkenes, a net oxidative cyclization process (Scheme 1). ${ }^{1 \mathrm{c}, \mathrm{f}}$ In depth mechanistic studies led us to conclude that the stereochemistry determining $\mathrm{C}-\mathrm{N}$ bond forming step occurred via syn aminocupration of the alkene (cf. $\mathbf{3} \rightarrow$ 5 via 4 , Scheme 1). ${ }^{1 f}$ If the copper salt is involved in the stereochemistry-determining step, chiral ligands on copper could allow for a stereocontrolled synthesis of the product. In the proposed $\mathrm{C}-\mathrm{N}$ bond-forming transition state $\mathbf{4}$, the substrate occupies two coordination sites on a tetracoordinate copper(II), ${ }^{4}$ leaving two coordination sites available for a bidentate ligand (Scheme 1). Inspired by this analysis, we initiated a search for an appropriate oxidant for copper turnover and ligand for asymmetric induction. Herein is reported the first catalytic as well as catalytic asymmetric variant of this copper(II)-facilitated carboamination reaction.

In the search for conditions catalytic in copper, we screened a number of oxidants $\left[\mathrm{O}_{2}, \mathrm{PhI}\right.$ $(\mathrm{OAc})_{2}$, oxone, $\mathrm{Me}_{3} \mathrm{NO}, \mathrm{MnO}_{2}$ ], with and without ligands in different solvents for the conversion of 1a to $2 \mathbf{a}$ with a catalytic amount ( 0.2 equiv) of copper(II) ethylhexanoate. The highest conversions were obtained with $\mathrm{MnO}_{2}$ ( 3 equiv) as oxidant in trifluorotoluene in the presence of ligands (Table 1). Under the optimized conditions but in the absence of copper(II), no reaction occurs. In toluene, a mixture of carboamination and hydroamination products $2 \mathbf{a}$ and 7 was observed (Table 1, entries 3 and 4). We hypothesized the hydroamination product 7 is formed via carbon radical (e.g. 6) capture of a hydrogen atom from solvent. Gratifyingly, changing the solvent to trifluorotoluene substantially decreased formation of the hydroamination adduct (Table 1, entries 5, 6 and 8). The carboamination reactions stoichiometric in copper(II) (cf. Scheme 1) start out blue [due to copper(II)] and terminate as orange-brown heterogeneous mixtures, indicating formation of copper(0), possibly from disproportionation of copper(I) to copper(II) and copper(0). Reoxidation of copper(0) under the mildly basic reaction conditions used in these reactions is challenging. We hypothesized that ligands would stabilize copper(I) and copper(II) in preference to copper(0). ${ }^{3}$ Addition of diethylsalicylamide $\mathbf{8}(0.2$ and 0.8 equiv) increased the reaction yields, likely due to improved copper turnover (Table 1, compare entries 1 and 2 with 3-6). ${ }^{5}$ We changed the copper(II) 
source to $\mathrm{Cu}(\mathrm{OTf})_{2}$ to achieve better ligand chelation (entries 6-8). The bipyridine ligand 9 ( 0.2 equiv) gave more efficient conversion when $\mathrm{Cu}(\mathrm{OTf})_{2}$ was used (compare entry 6 to 8 ).<smiles>CCNC(=O)c1ccccc1O</smiles>

We screened chiral ligands $\mathbf{1 0 - 1 3}$ by precomplexing $\mathrm{Cu}(\mathrm{OTf})_{2}(0.2$ equiv) with ligand ( 0.2 equiv) followed by addition of substrate $1 \mathrm{a}, \mathrm{K}_{2} \mathrm{CO}_{3}$ (1 equiv) and $\mathrm{MnO}_{2}$ ( 3 equiv) and heating in a sealed tube for $24 \mathrm{~h}$ in $\mathrm{PhCF}_{3}$ (Table 2).

We quickly found that 2,2-bis[(4R)-4-phenyl-2-oxazolin-2-yl]propane (11a) gave the highest asymmetric induction, providing carboamination adduct 2a in $85 \%$ isolated yield, $92 \%$ enantiomeric excess (Table 2, entry 5). We were unable to reduce the catalyst loading below 0.2 equiv without adversely affecting the product yield (Table 2, entries 10 and 11). Lowering the reaction temperature to $110^{\circ} \mathrm{C}$ provided the product in slightly lower yield (72\%) and $94 \%$ enantiomeric excess (Table 2, entry 12). Ligands $\mathbf{1 2}$ and $\mathbf{1 3}$ rendered the copper(II) complex less reactive (entries 8 and 9).

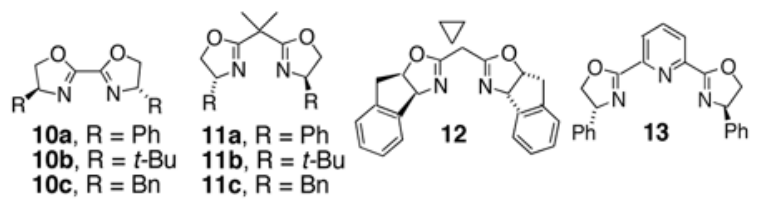

The generality of the reaction was examined as shown in Table 3. $\gamma$-Alkenyl arylsulfonamides 1 cyclized in 45-85\% yield and 80-94\% ee. ${ }^{6}$ The 2-sulfamido thiophene substrate 14 reacted very sluggishly but with good enantioselectivity. $N$-Tosyl-2-allylaniline $\mathbf{1 6}$ reacted efficiently but with low (46\%) enantioselectivity and $N$-tosyl-2-allylbenzylamine 18 reacted sluggishly and in moderate yield and enantioselectivity to provide tetrahydroisoquinoline $\mathbf{1 9}$ (entry 12).

$\mathrm{X}$-Ray crystal structures of sultams $\mathbf{2 g}$ and $\mathbf{1 5}$ indicate the (S)-configuration. The other carboamination adducts in Table 3 are assigned the S stereochemistry by analogy. Sultam $2 \mathbf{i}$ was converted to the known 2(S)-benzylpyrrolidine $\mathbf{2 0},{ }^{7}$ an intermediate used in the synthesis of a potent calcium-sensing receptor antagonist, ${ }^{8}$ by reductive removal of $\mathrm{SO}_{2}$ (Scheme 2). Pyrrolidine $(S)$-20 is thus available by this method in three steps from commercially available starting materials (see Supporting Information for complete details).

The observed stereochemistry is consistant with transition state $\mathbf{A}$ (Scheme 2), where the substrate's $N$-substituent is on the face opposite of the oxazoline phenyl substituent it is cis to about the distorted square planar copper center. ${ }^{4}$

The method reported herein provides access to enantiomerically enriched nitrogen heterocycles. Applications of this reaction toward the synthesis of bioactive compounds are underway. This method will also inspire the development of other copper(II)-catalyzed enantioselective amination reactions.

\section{Supplementary Material}

Refer to Web version on PubMed Central for supplementary material. 


\section{Acknowledgements}

The financial support of the NIH/NIGMS RO1 GM078383 is gratefully acknowledged. Dr. Shao-Liang Zheng (SUNY, Buffalo X-ray crystallography facility) is gratefully acknowledged for obtaining crystal structures of $\mathbf{2 g}$ and $\mathbf{1 5}$.

\section{References}

1. (a) Larock RC, Yang H, Weinreb SM, Herr RJ. J Org Chem 1994;59:4172. (b) Harayama H, Abe A, Sakado T, Kimura M, Fugami K, Tanaka S, Tamaru Y. J Org Chem 1997;62:2113. [PubMed: 11671516] (c) Sherman ES, Chemler SR, Tan TB, Gerlits O. Org Lett 2004;6:1573. [PubMed: 15128239] (d) Yip KT, Yang M, Law KL, Zhu NY, Yang D. J Am Chem Soc 2006;128:3130. [PubMed: 16522078] (e) Scarborough CC, Stahl SS. Org Lett 2006;8:3251. [PubMed: 16836378] (f) Sherman ES, Fuller PH, Kasi D, Chemler SR. J Org Chem 2007;72:3896. [PubMed: 17428100] (g) Peng J, Lin W, Yuan S, Chen Y. J Org Chem 2007;72:3145. [PubMed: 17367194] (h) Bertrand MB, Leathen ML, Wolfe JP. Org Lett 2007;9:457. [PubMed: 17249786] (j) Nakhla JS, Wolfe JP. Org Lett 2007;9:3279. [PubMed: 17650007] (i) Wolfe JP. Eur J Org Chem 2007:571.and references therein

2. Sammes, PG. Chap. 7.1. In: Hansch, C.; Sammes, PG.; Taylor, JB., editors. Comprehensive Medicinal Chemistry. 2. Pergamon Press; Oxford: 1990. (b) Wilkening RR, Ratcliffe RW, Wildonger KJ, Cama LD, Dykstra KD, DiNinno FP, Blizzard TA, Hammond ML, Heck JV, Dorso KL, Rose ESt, Kohler J, Hammond GG. Bioorg Med Chem Lett 1999;9:673. [PubMed: 10201827]

3. Chemler SR, Fuller PH. Chem Soc Rev 2007;36:1153. [PubMed: 17576482] and references therein

4. Johnson JS, Evans DA. Acc Chem Res 2000;33:325. [PubMed: 10891050]

5. Kwong FY, Buchwald SL. Org Lett 2003;5:793. [PubMed: 12633073]

6. A homologue of 1a, one carbon longer in the chain, did not react.

7. Burgess LE, Meyers AI. J Org Chem 1992;57:1656.

8. Yang W, Wang Y, Roberge JY, Ma Z, Liu Y, Lawrence RM, Rotella DP, Seethala R, Feyen JH, Dickson JK. Bioorg Med Chem Lett 2005;15:1225. [PubMed: 15686947] 


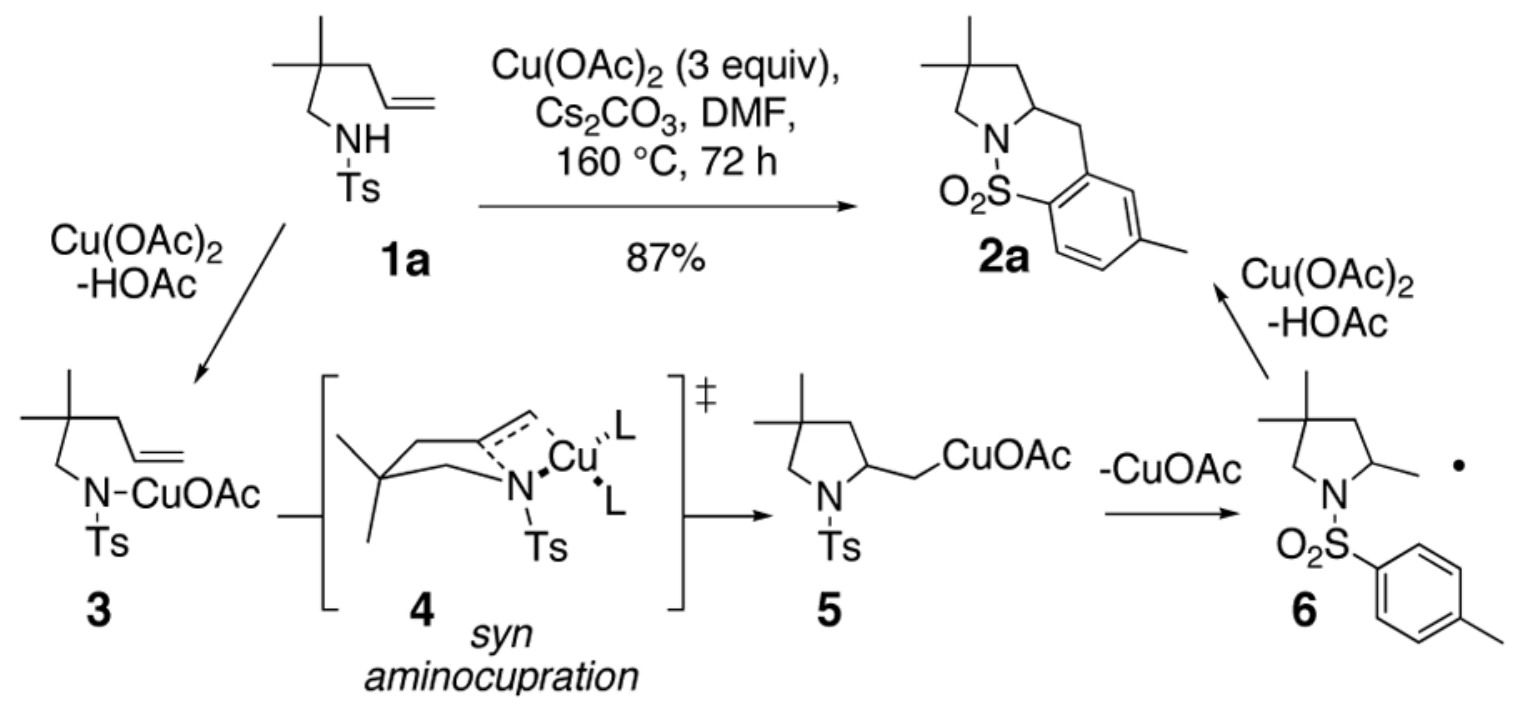

Scheme 1.

Copper(II)-Promoted Carboamination and Mechanism 


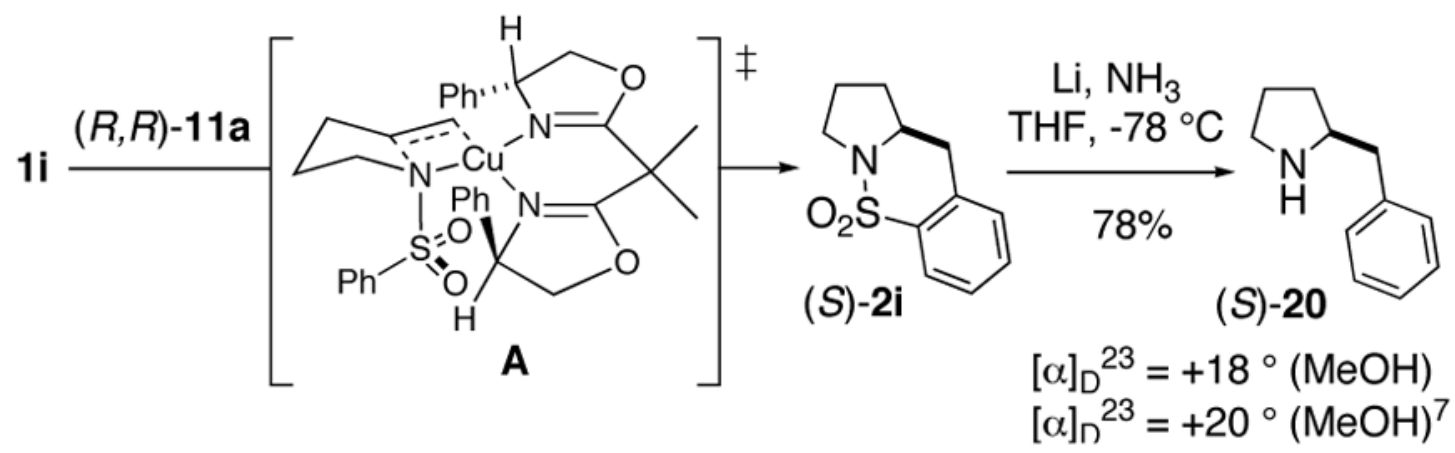

Scheme 2.

Transition State Model and Removal of $\mathrm{SO}_{2}$ 


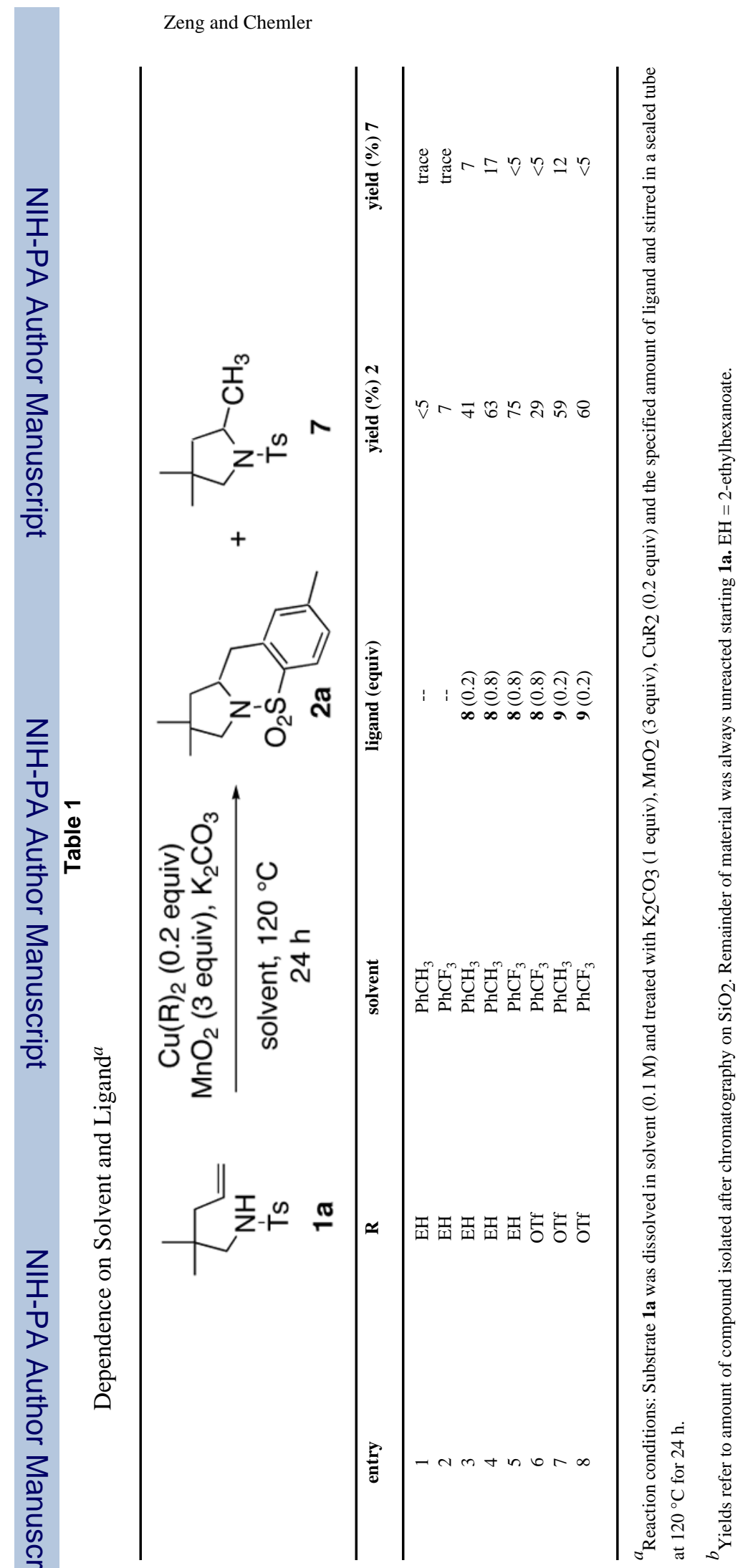

Page 6

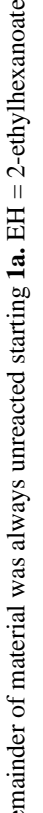




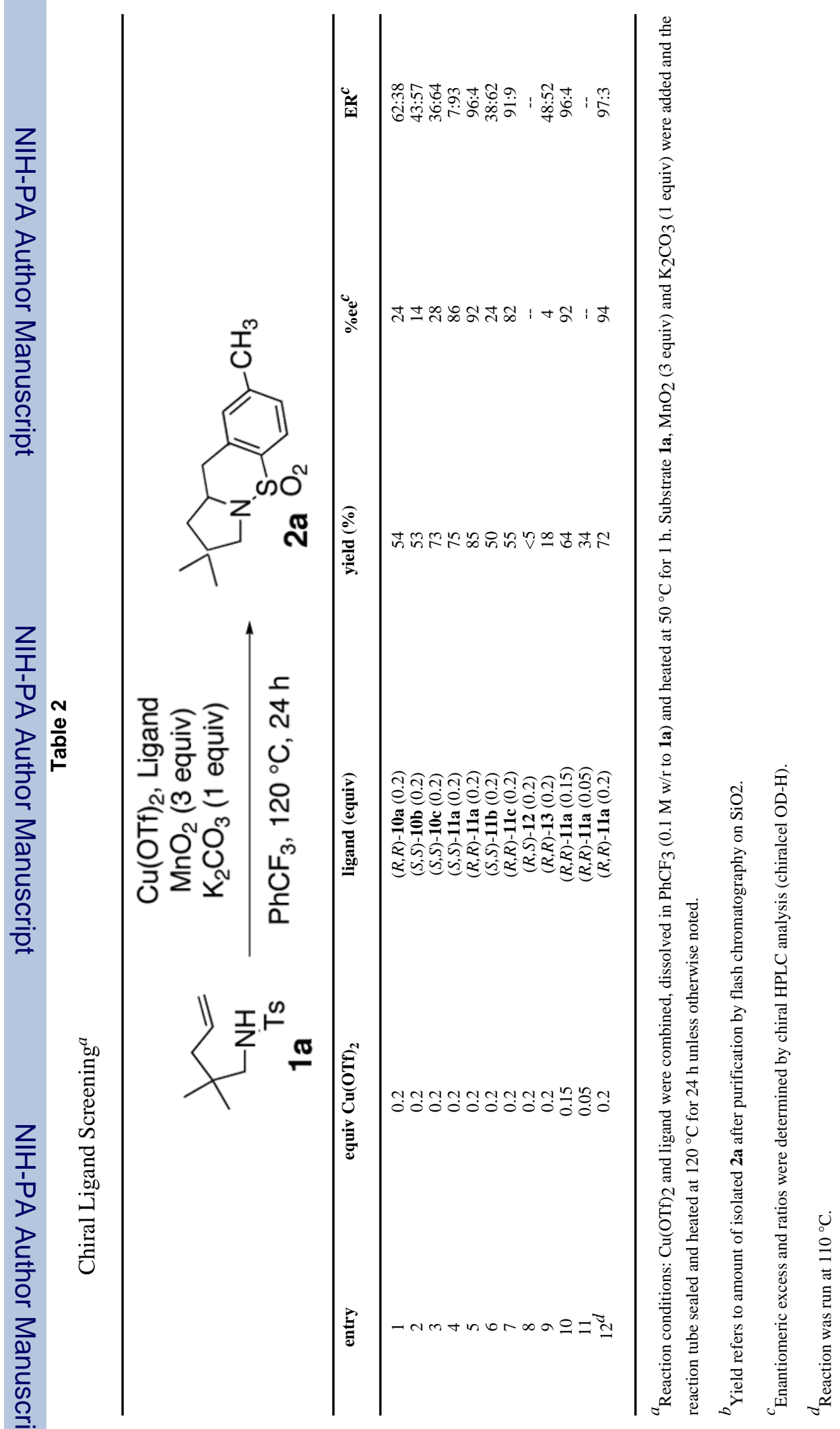




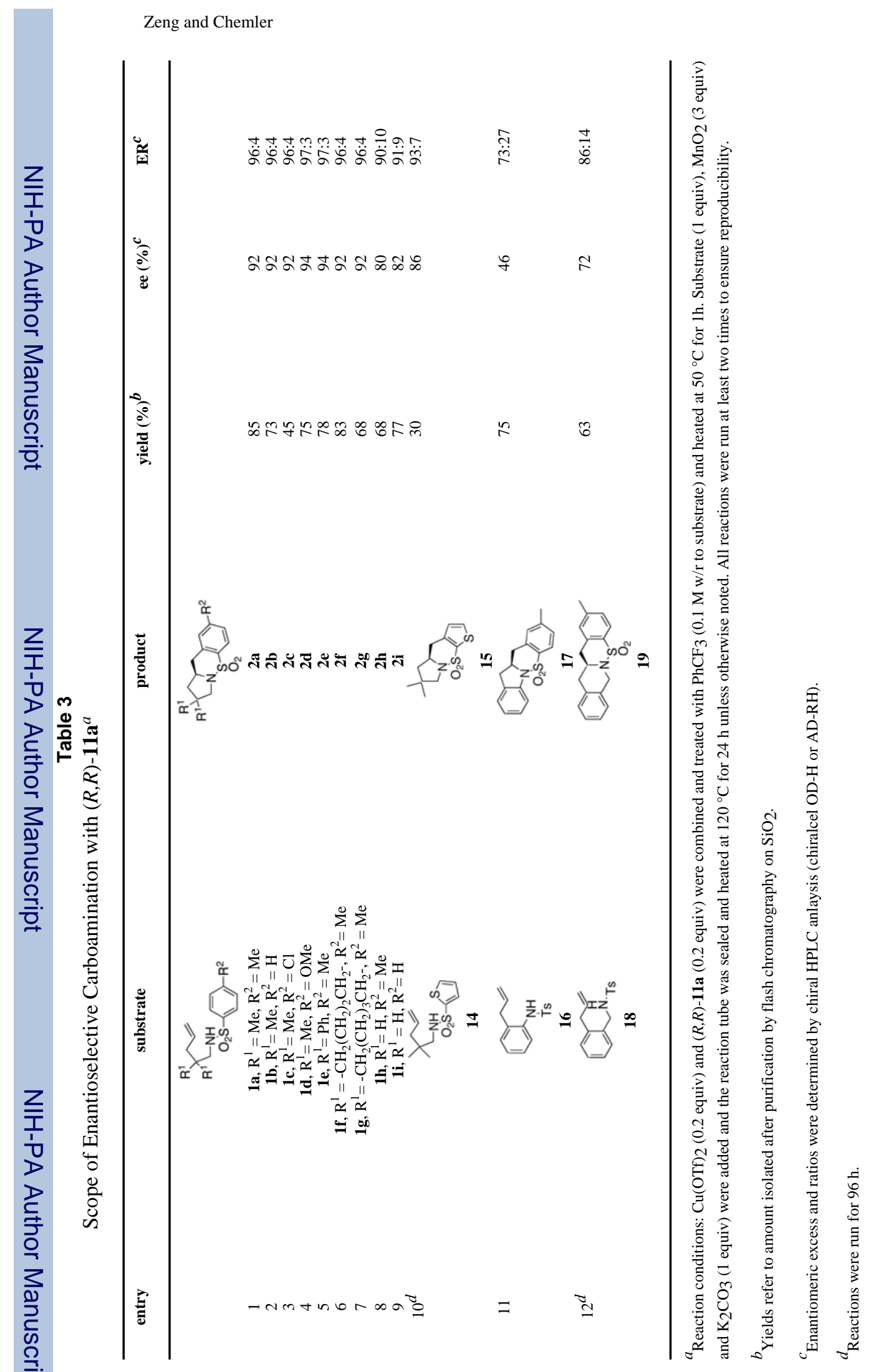

$J$ Am Chem Soc. Author manuscript; available in PMC 2008 October 31. 